\title{
Phenformin as prophylaxis and therapy in breast cancer xenografts
}

\author{
MVCL Appleyard*,', KE Murray', PJ Coates', S Wullschleger², SE Bray', NM Kernohan ${ }^{3}$, S Fleming', DR Alessi $^{2}$ \\ and AM Thompson ${ }^{1,4}$
}

'Centre for Oncology and Molecular Medicine, University of Dundee, Dundee DDI 9SY, UK: ${ }^{2}$ MRC Protein Phosphorylation Unit, University of Dundee, Dundee DDI 9SY, UK; ${ }^{3}$ Division of Pathology and Neuroscience Ninewells Hospital and Medical School, University of Dundee, Dundee DDI 9SY, UK:

${ }^{4}$ Department of Surgical Oncology, MD Anderson Cancer Center, 1400 Holcombe Boulevard, Houston, Texas 77030, USA

BACKGROUND: Observations that diabetics treated with biguanide drugs have a reduced risk of developing cancer have prompted an enthusiasm for these agents as anti-cancer therapies. We sought to determine the efficacy of the biguanide phenformin in the chemoprophylaxis and in the treatment of oestrogen receptor (ER)-positive MCF7 and receptor triple-negative MDAMB23I xenografts in immunocompromised mice. We also compared the efficacy of phenformin and metformin in the treatment of MDAMB23I.

METHODS: Immunocompromised mice were divided into groups: (I) phenformin administered for 2 weeks prior to cell injection; (2) established tumours treated with phenformin; (3) established tumours treated with metformin (only for MDAMB23I tumours); (4) untreated controls. Post-treatment tumours, liver and spleen were harvested for further analysis.

RESULTS: Phenformin significantly inhibited both the development and growth of MCF7 and MDAMB23I tumours, and for MDAMB23 I at greater efficacy than metformin without murine toxicity. The number of mitotic figures was significantly fewer in xenografts treated with phenformin compared with controls. Results suggested that the mechanism of action of phenformin in vivo is consistent with AMPK activation.

CONCLUSION: Phenformin has clinical potential as an antineoplastic agent and should be considered for clinical trials both in ER-positive and triple-negative breast cancer.

British Journal of Cancer (2012) 106, III7-II22. doi:I0.1038/bjc.2012.56 www.bjcancer.com

Published online 23 February 2012

(c) 2012 Cancer Research UK

Keywords: breast cancer; phenformin; metformin; xenografts; therapy

Despite advances in the treatment of and survival from breast cancer, there remains a need to establish additional anti-cancer therapies. Although cancer therapeutics, including those directed against HER2 or PARP, have been developed through intelligent design and other promising agents have emerged from screening assays (Lain et al, 2008; Staples et al, 2008), the additional and unexpected antineoplastic effect of drugs used in the treatment of non-malignant conditions has been highlighted using epidemiological approaches (Demierre and Nathanson, 2003; Sausville et al, 2003). As an exemplar, diabetics treated with biguanide drugs have a reduced risk of developing cancer compared with that of patients receiving sulfonylurea (Evans et al, 2005; Landman et al, 2010). Metformin is a widely used oral biguanide that originates from the French lilac (Galega officinalis), a plant known for several centuries to reduce the symptoms of diabetes mellitus (Chong and Chabner, 2009). Phenformin is a factorially more active drug against tumour cells (Huang et al, 2008), but use as an antidiabetic agent has been limited to relatively few countries (including Italy, Greece, Portugal, Poland, Brazil and Uruguay) because of an increased incidence, compared with metformin, of phenformin-associated lactic acidosis, usually in elderly patients with renal failure (McGuinness and Talbert, 1993).

*Correspondence: Dr MVCL Appleyard;

E-mail: m.v.c.l.appleyard@dundee.ac.uk

Received 26 September 2011; revised 25 January 2012; accepted 26 January 2012; published online 23 February 2012
The biguanides act as oral hypoglycaemic agents primarily through suppression of hepatic glucose production, but also by increased insulin sensitivity, enhanced peripheral glucose uptake, decreased fatty-acid oxidation and decreased absorption of glucose from the gastrointestinal tract (Bailey and Turner, 1996; Kirpichnikov et al, 2002).

At the cellular level, biguanides work through activation of AMPK (Zhou et al, 2001; Kim et al, 2008) in a mechanism that requires LKB1 (Shaw et al, 2005; Huang et al, 2008) and involves regulation of the downstream pathways relevant to the control of cellular proliferation (Kahn et al, 2005), resulting in a variety of effects distinct from their anti-diabetic activity.

In 1968, Lugaro and Giannattasio (1968) described anti-tumour effects of biguanidides. Since then, many other authors have described anti-tumour activity of biguanides in animal models and cell lines. For instance, phenformin has been shown to exert antitumour activity in different animal models (Dilman and Anisimov, 1980; Caraci et al, 2003) and to enhance the anti-tumour effects of established chemotherapy agents against squamous cell carcinoma, hepatoma-22a and lung cancer in mice (Dilman and Anisimov, 1979). Treatment of the neuroblastoma SH-SY5Y tumour cell line with increasing concentrations of phenformin reduced tumour proliferation and induced apoptosis (Caraci et al, 2003). Prophylactic treatment with phenformin was also reported to decrease the incidence of DMBA-induced mammary tumours in rats (Dilman et al, 1978).

The potential of biguanides for the prevention and treatment of cancer has focused to date on metformin, widely used in clinical 
diabetic practice, with clear associations between metformin use in diabetics and the prevention of breast cancer (Evans et al, 2005) and increased efficacy of chemotherapy against breast cancer in the neoadjuvant setting (Jiralerspong et al, 2009). Indeed, clinical trials using metformin alone or in combination with other therapies in breast cancer are now underway including in the neoadjuvant (Hadad et al, 2011) and adjuvant setting (Goodwin et al, 2009).

This enthusiasm for metformin has been supported by models of mouse mammary adenocarcinoma in which metformin treatment significantly decreased the incidence and size of the tumours (Anisimov et al, 2005) and inhibited the growth of transplantable HER 2 mammary carcinoma in mice by $46 \%$ (Anisimov et al, 2010). There is some controversy regarding efficacy of metformin against triple-negative breast cancer, with reports of growth inhibition of tumour (Liu et al, 2009), but also triple-negative breast cancer resistance to metformin (Zhuang and Miskimins, 2008, 2011).

Extending the biguanide class effect beyond metformin, a role for phenformin as a potential anti-cancer agent has recently been demonstrated in a physiological signalling pathway that may inhibit cell growth (Huang et al, 2008). Moreover, it has been recently reported that when administered in combination with 2-deoxyglucose, lactic acidosis may be avoided and as phenformin is a more potent drug than metformin, phenformin should be re-examined as a potential agent in cancer therapy (Lea et al, 2011).

In the present study, we investigated the efficacy of phenformin in preventing or repressing the growth of tumour xenografts derived from oestrogen receptor (ER)-positive luminal-type MCF7 and receptor triple-negative MDAMB231 breast cancer cell lines and examined the tumour-specific and systemic effects of phenformin on cell proliferation and components of the AMPK and the cell-cycle pathways. We also compared the efficacy of metformin and phenformin against MDAMB231 breast cancer tumour xenografts.

\section{MATERIALS AND METHODS}

\section{Cell culture and media}

MCF7 and MDA-MB-231 cells were acquired from ATCC (LGC Standards, Teddington, UK) and used immediately. Prior to harvesting, cells were grown in DMEM containing $10 \%$ fetal calf serum and $1 \%$ penicillin/streptomycin at $37{ }^{\circ} \mathrm{C}$ with $5 \% \mathrm{CO}_{2}$ to $80 \%$ confluence. Cultured human breast cancer cells were tested for mycoplasma (MycoAlert from Lonza Wokingham Ltd, Slough, UK) prior to harvesting. Mycoplasma-free cells were trypsinised, harvested, rinsed and then suspended in 50:50 DMEM and matrigel (BD Biosciences, Two Oak Park, Bedford, MA, USA). The suspension was kept below $4{ }^{\circ} \mathrm{C}$ at all times.

\section{Xenografts}

Studies were carried out under licence 60/3729 in accordance with the guidelines of the UKCCCR. Female nude (nu/nu) mice for MCF7 studies or female SCID mice for MDAMB231 studies (both from Harlan, Loughborough, UK) were housed under aseptic conditions in individually ventilated cages in a temperature$\left(24^{\circ} \mathrm{C}\right)$ and light-controlled (12 h per day) environment, and received autoclaved food and water ad libidum. Nude mice were implanted with $17 \beta$-estradiol pellets $(0.72 \mathrm{mg}$ per pellet) from Innovative Research of America (Sarasota, FL, USA) at least 2 days before injection into each flank of $1 \times 10^{8}$ MCF7 cells in $100 \mu$ l of a 50:50 DMEM and matrigel suspension. SCID mice were injected subcutaneously in both flanks with $1 \times 10^{8}$ MDAMB231 cells in $100 \mu \mathrm{l}$ of a 50:50 DMEM and matrigel suspension.

\section{Treatment regime}

Mice were randomly divided into groups of 10 mice each and treated as shown in Table 1 . In summary, for group 1, 2 weeks prior to injection of MCF7 or MDAMB231, drinking water was replaced with $5 \%$ sucrose containing phenformin $\left(300 \mathrm{mg} \mathrm{kg}^{-1}\right)$ (pre-treated group). The addition of sucrose was because of palatability. When tumours were $\geqslant 30 \mathrm{~mm}^{3}$, water for the mice of the second group was replaced with $5 \%$ sucrose containing phenformin $\left(300 \mathrm{mg} \mathrm{kg}^{-1}\right)$ and mice of the third group remained untreated as controls, but water was replaced with 5\% sucrose. In the case of MDAMB231 tumours, a fourth group had water added with metformin $\left(300 \mathrm{mg} \mathrm{kg}^{-1}\right)$. In the case of metformin, palatability was not an issue and the controls in group 5 did not have sucrose added to their water. Drug concentration was based on literature data (Huang et al, 2008).

\section{Tumour measurements}

Tumour dimensions and mouse weights were measured twice a week using callipers by one of the authors (MA or KM). Tumour sizes were calculated using the formula $V=4 / 3 \pi((\mathrm{d} 1+\mathrm{d} 2) /$ $4)^{3} \mathrm{~mm}^{3}$. Tumour volumes at the end of treatment were compared using Student's $t$-test.

\section{Tissue processing}

When appropriate, animals were killed and tumours were removed, cut in half, each half either fixed in $10 \%$ buffered formalin or snap frozen, respectively. Non-tumour tissues (liver and spleen) were snap frozen. Mouse tissues and xenograft tumours were prepared for western blotting or histology and immunohistochemistry analysis as described below.

\section{Immunohistochemistry}

Sections from formalin-fixed paraffin-embedded xenograft tissue ( $4 \mu \mathrm{m}$ thick) were cut onto poly-L-lysine-coated glass slides (VWR International Ltd, Leighton Buzzard, UK) and dried for $1 \mathrm{~h}$ at $60^{\circ} \mathrm{C}$ before being de-paraffinised in Histoclear (National Diagnostics Ltd, Hessle, UK). After blocking endogenous peroxidase activity in $0.5 \% \mathrm{H}_{2} \mathrm{O}_{2}$ (100 volumes) in methanol for $35 \mathrm{~min}$ at room temperature, antigen retrieval was performed by boiling in $10 \mathrm{~mm}$ citric acid buffer, $\mathrm{pH}$ 6.0, for $15 \mathrm{~min}$ in a microwave oven operating at full power. Sections were allowed to cool, washed in PBS and non-specific antibody-binding blocked in 5\% normal goat serum for $30 \mathrm{~min}$ at room temperature. Primary rabbit antibodies

Table I Treatment regime for MCF7 and MDAMB23I xenografts using phenformin and metformin

\begin{tabular}{|c|c|c|}
\hline Cell line & MCF7 & MDAMB23 I \\
\hline Group I (pre-treated) & Phenformin in $5 \%$ sucrose added 2 weeks prior to cell injection & Phenformin in $5 \%$ sucrose added 2 weeks prior to cell injection \\
\hline Group 2 & Phenformin in $5 \%$ sucrose added after tumour development & Phenformin in $5 \%$ sucrose added after tumour development \\
\hline Group 3 & Untreated control (water replaced with 5\% sucrose) & Untreated control (water replaced with $5 \%$ sucrose) \\
\hline Group 4 & - & Metformin in drinking water added after tumour development \\
\hline Group 5 & - & Untreated control \\
\hline
\end{tabular}


to phospho-histone H3 (Ser10) or cleaved PARP (Asp 214) (Cell Signaling Technology no. 9701 or no. 9541, respectively, New England Biolabs, Hitchin, UK) were diluted in 5\% normal goat serum and incubated overnight at $4{ }^{\circ} \mathrm{C}$. For Ki67 staining, a rat monoclonal anti-Ki67 (Clone TEC-3; DakoCytomation, Dako UK Ltd, Ely, UK) was diluted $1 / 500$ in $5 \%$ normal rabbit serum. After washing in PBS, sections were incubated with biotinylated goatanti-rabbit immunoglobulins diluted $1 / 250$ in $5 \%$ normal goat serum or with biotinylated rabbit anti-rat IG (mouse adsorbed, Vector Laboratories Ltd, Peterborough, UK) diluted 1/250 in 5\% normal rabbit serum, washed in PBS and incubated with avidinbiotinylated peroxidase complex in PBS using Vectastain Elite ABC kit reagents (Vector Labs). Immunoreactive sites were identified with diaminobenzidine $/ \mathrm{H}_{2} \mathrm{O}_{2}$ in PBS containing $5 \mathrm{~mm}$ imidazole, $\mathrm{pH}$ 7.0, for $10 \mathrm{~min}$ and sections counterstained with Mayer's haematoxylin before dehydrating, mounted with coverslips using DPX and viewed using light microscopy.

\section{Histology}

The morphology of the tumours was assessed by haematoxylinand eosin-stained sections. To assess changes in collagen content in treated tumours, Van Gieson staining was performed. Because formalin-fixed tissues can be significantly affected by differences in fixation time rendering TUNEL assays unreliable in many cases, to assess apoptosis and mitosis in tumour tissues, sections from formalin-fixed paraffin-embedded xenograft tissue were stained with Hematoxylin and Eosin. Cells in 20 microscopic fields were counted and the percentage of mitotic and apoptotic cells determined. Populations were compared using a two-tailed, two-sample equal variance Student's $t$-test.

\section{Western blots}

To confirm the activation of the AMPK pathway by phenformin in vivo in these murine models, AMPK, phospho-AMPK, was examined in the liver, spleen and tumours of treated mice. Tissues were homogenised on ice in a 10-fold mass excess of ice-cold lysis buffer comprising $50 \mathrm{~mm}$ Tris- $\mathrm{HCl}, \mathrm{pH} 7.5,1 \mathrm{~mm}$ EGTA, 1\% (w/v) Triton-X 100, $1 \mathrm{~mm}$ sodium orthovanadate, $50 \mathrm{~mm}$ sodium fluoride, $5 \mathrm{~mm}$ sodium pyrophosphate, $0.27 \mathrm{M}$ sucrose, $0.1 \%(\mathrm{v} / \mathrm{v})$ 2-mercaptoethanol and 'Complete' protease inhibitor cocktail (Roche Diagnostics Ltd, Burgess Hill, UK) using a Kinematica Polytron homogeniser (Kinematica Inc., Bohemia, NY, USA). Tissue lysates were centrifuged at $18000 \mathrm{~g}$ for $15 \mathrm{~min}$ at $4{ }^{\circ} \mathrm{C}$ and the supernatant was snap frozen and stored at $-80^{\circ} \mathrm{C}$. The protein concentration was determined by Bradford assay (Pierce-Fisher Scientific Ltd, Loughborough, UK). Total tissue lysate $20 \mu \mathrm{g}$ was heated at $70{ }^{\circ} \mathrm{C}$ for $5 \mathrm{~min}$ in SDS - PAGE sample buffer ( $50 \mathrm{~mm}$ Tris$\mathrm{HCl}, \mathrm{pH} 6.8,6.5 \%(\mathrm{v} / \mathrm{v})$ glycerol, $1 \%(\mathrm{w} / \mathrm{v})$ SDS and $1 \%(\mathrm{v} / \mathrm{v}) 2-$ mercaptoethanol), subjected to PAGE and electrotransferred to nitrocellular membranes. Membranes were blocked for $1 \mathrm{~h}$ in TBSTween (50 mM Tris- $\mathrm{HCl}, \mathrm{pH} 7.5,0.15 \mathrm{M} \mathrm{NaCl}$ and $0.1 \%$ Tween 20 ) containing $10 \%(\mathrm{w} / \mathrm{v})$ skimmed milk powder and probed with the indicated antibodies in TBS-Tween containing 5\% (w/v) BSA for $16 \mathrm{~h}$ at $4{ }^{\circ} \mathrm{C}$. Detection was performed using horseradish peroxidase-conjugated secondary antibodies (Pierce) and ECL reagent. Anti-AMPK $\alpha 1$, raised in sheep against the peptide CTSPPDSFLDDHHLTR (residues $344-358$ of rat AMPK $\alpha 1$ ), and AMPK $\alpha$ p-T172 (no. 2535) were purchased from Cell Signaling Technology.

\section{RESULTS}

\section{Efficacy of phenformin in an MCF7 xenograft model}

Mice pre-treated with phenformin had delayed establishment of tumours that were fewer in number: after 4 weeks, $25 \%$ of mice developed tumours that reached a mean $24 \mathrm{~mm}^{3}$. In contrast, without phenformin pre-treatment, 3 weeks after inoculation, $60 \%$ of untreated mice had tumours. Established MCF7 tumours treated with phenformin had $88 \%$ inhibition of tumour growth relative to the control group (Student's $t$-test $P<0.05$ ) (Figure 1A).

\section{Efficacy of phenformin in an MDAMB231 xenograft model}

In the MDAMB231 xenograft model, $60 \%$ of the untreated animals had measurable tumours 5 weeks after inoculation, whereas mice treated prophylactically with phenformin showed small, static
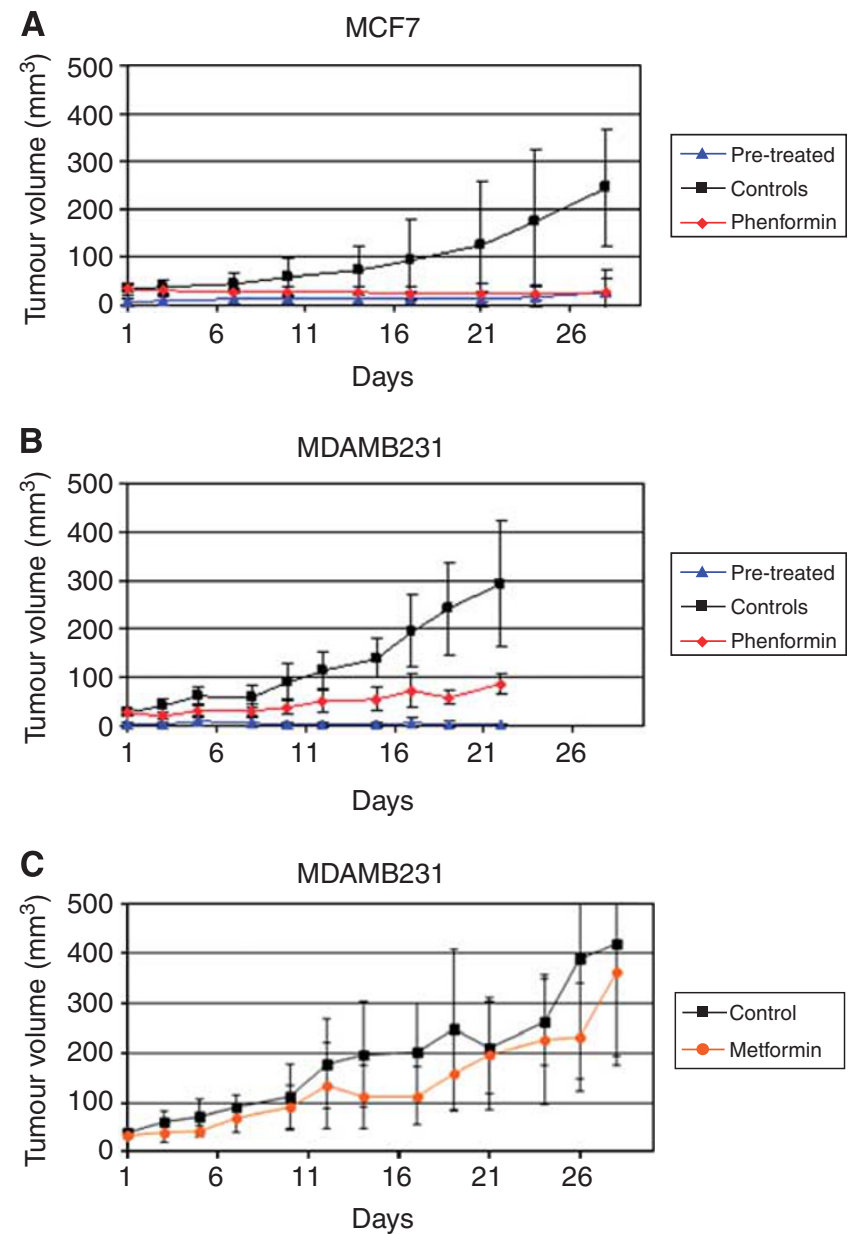

Figure I Effect of $300 \mathrm{mg} \mathrm{kg}^{-1}$ phenformin on human breast MCF7 (A) and MDAMB23। (B), and $300 \mathrm{mg} \mathrm{kg}^{-1}$ metformin on MDAMB23। (C) tumour xenografts. For the phenformin experiment, mice were divided into three groups. Controls received no phenformin. Pre-treatment mice were given phenformin $\left(300 \mathrm{mg} \mathrm{kg}^{-1}\right)$ in $5 \%$ sucrose instead of normal drinking water for 2 weeks prior to injection of MCF7 or MDAMB23I cells. The phenformin group received normal drinking water until tumours reached $\geqslant 30 \mathrm{~mm}^{3}$, after which drinking water was replaced with $5 \%$ sucrose containing phenformin $\left(300 \mathrm{mg} \mathrm{kg}^{-1}\right)$. Control group also had water replaced with $5 \%$ sucrose. For the metformin experiment, mice were divided into two groups. Controls received no metformin and mice with established tumours received metformin $\left(300 \mathrm{mg} \mathrm{kg}^{-1}\right)$ in water. MCF7 tumours pre-treated or treated with phenformin had statistically significant inhibition of tumour growth of $88 \%$ relative to the control group $(P<0.05)$. Animals injected with MDAMB23 I cells and treated prophylactically with phenformin showed small lumps 6 weeks after inoculation, which remained static for the rest of the experiment. Established MDAMB23I tumours treated with phenformin demonstrated statistically significant inhibition of tumour growth of $60 \%$ relative to the control group $(P<0.05)$. There were no statistically significant differences between control mice and mice treated with metformin. 
lumps 6 weeks after inoculation. Established MDAMB231 tumours treated with phenformin demonstrated statistically significant inhibition of tumour growth of $60 \%$ relative to the control group (Student's $t$-test $P<0.05$ ) (Figure 1B).

\section{Efficacy of metformin in an MDAMB231 xenograft model}

Established MDAMB231 tumours treated with metformin did not show statistically significant inhibition of tumour growth compared with the control group (Figure 1C).

\section{Histology}

Histological examination confirmed that the tumours consisted of high-grade adenocarcinomas. Hematoxylin- and Eosin-stained MCF7 control tumours showed $1.4 \pm 0.8 \%$ apoptotic cells and $1.4 \pm 0.8 \%$ mitotic cells. In tumours treated with phenformin, the percentage of apoptotic cells was $1.05 \pm 0.6 \%$, not significantly different to control tumours $(P>0.05)$. However, the number of mitotic cells significantly decreased in treated tumours compared with untreated controls $(0.18 \pm 0.2 \%, P<0.05$, Student's $t$-test $)$. The same pattern was observed for MDAMB231 tumours, where the number of apoptotic cells remained unchanged upon treatment with phenformin $(0.7 \pm 0.38 \%$ for control tumours and $0.61 \pm 0.29 \%$ for phenformin-treated tumours, $P>0.05$, Student's $t$-test), but there was a significant decrease in the proportion of mitotic cells in phenformin-treated tumours $(0.4 \pm 0.24 \%)$ compared with controls $(0.9 \pm 0.46 \%)(P<0.005$, Student's $t$-test $)$.

In MCF7 tumours treated with phenformin, there was an increase in stromal connective tissue but not proliferation compared with control tumours, observed with Van Gieson staining used to differentiate between collagen and smooth muscle (Figures 2A and B). MDAMB231 tumours, however, did not show differences in the amount of stromal connective tissue between phenformin-treated and control tumours (Figures 2C and D).

\section{Immunohistochemistry}

No significant differences were observed in immunohistochemical detection of phospho-histone $\mathrm{H} 3$, a well-established marker for
A

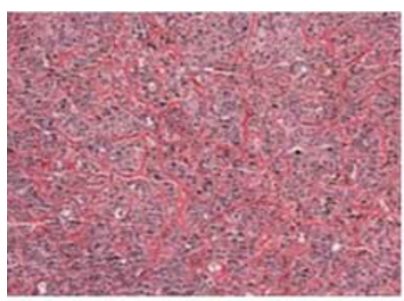

C MDAMB231 - Control

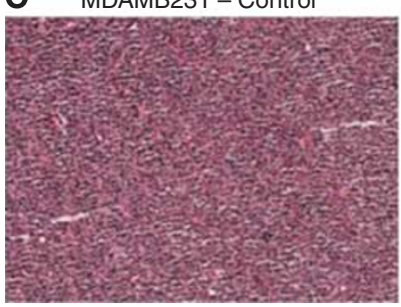

B $\quad$ MCF7 - Phenformin

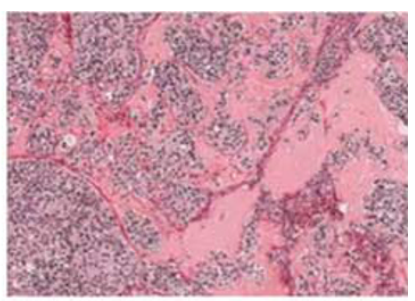

D MDAMB231 - Phenformin

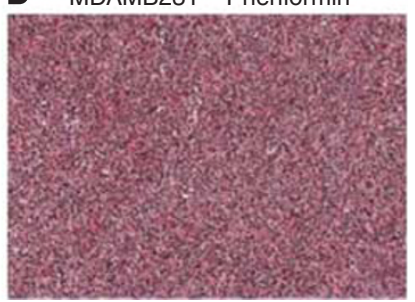

Figure 2 Connective tissue histological analysis of MCF7 and MDAMB23 I xenografts treated with phenformin using Van Gieson stain. MCF7 tumours treated with phenformin showed substantial increase of connective tissue, demonstrated as red/pink staining, which replaces epithelial tumour cells ( $\mathbf{A}$ and $\mathbf{B}$ ). No differences were observed in MDAMB23 I tumours $(\mathbf{C}$ and $\mathbf{D}), \times 5$ magnified image captured with an Aperio ScanScope XT, Aperio Technologies, Vista, CA, USA. mitosis (Figure 3), cleaved PARP, a marker for apoptosis (Figure 4), or the proliferation marker Ki67 (Figure 5) between control tumours and the two therapeutic regimes: tumours from phenformin pre-treated mice and established tumours treated with phenformin.

\section{AMPK activation analysed by western blot}

Phosphorylation of the activation loop of AMPK (T172) was enhanced in liver, spleen (Figure 6) and tumour lysates (Figure 7) derived from mice administered with phenformin compared with untreated control mice.
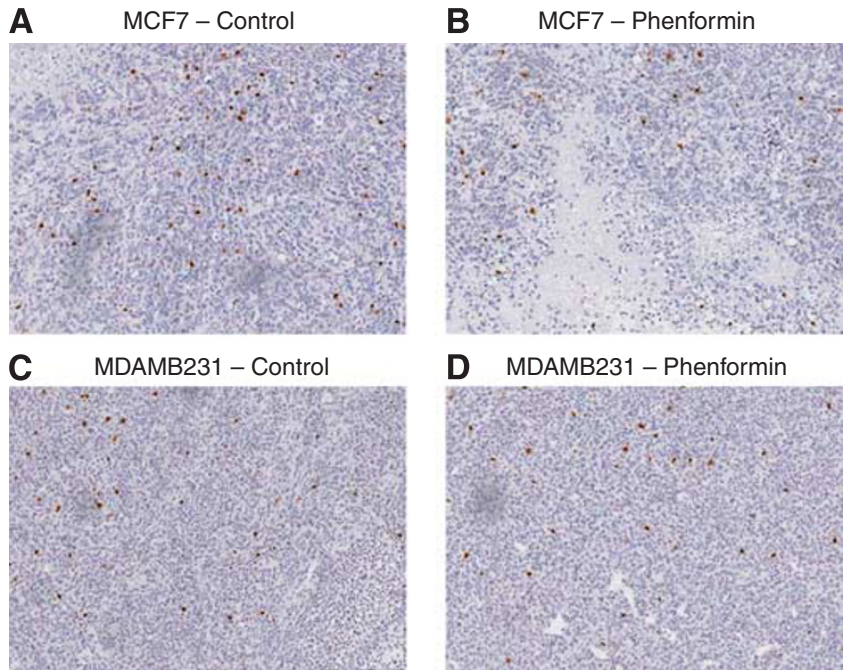

Figure 3 Phospho-histone $\mathrm{H} 3$ immunohistochemistry analysis of MCF7 and MDAMB23I xenografts treated with phenformin. Tumours were harvested and immunohistochemistry analysis performed as described in Materials and methods. No significant differences were observed for phenformin (B and D) compared with untreated MCF7 and MDAMB23। tumours $(\mathbf{A}$ and $\mathbf{C}), \times 5$ magnified image captured with an Aperio ScanScope XT, Aperio Technologies.
A

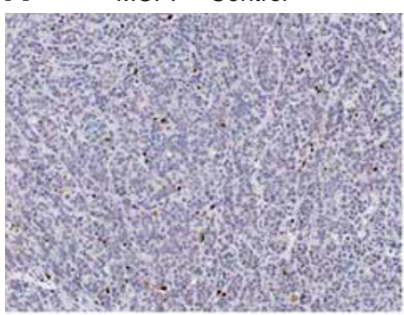

C

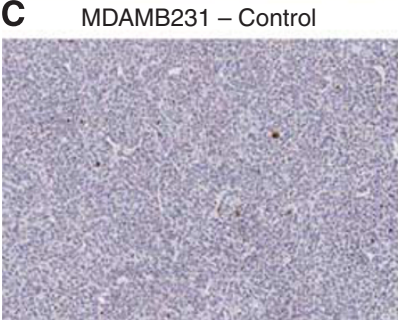

B MCF7 - Phenformin

D MDAMB231 - Phenformin

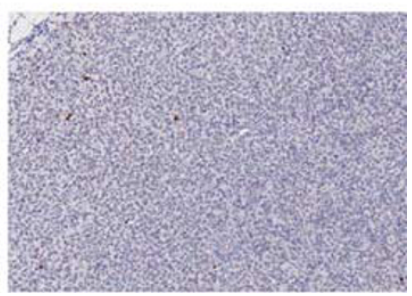

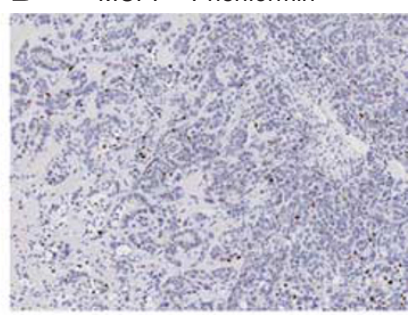

Figure 4 Cleaved PARP analysis of MCF7 and MDAMB23I xenografts treated with phenformin. Tumours were harvested and immunohistochemistry analysis performed as described in Materials and methods. No significant differences were observed for phenformin (B and $\mathbf{D})$ compared with untreated MCF7 and MDAMB23I tumours $(\mathbf{A}$ and $\mathbf{C}), \times 5$ magnified image captured with an Aperio ScanScope XT, Aperio Technologies. 

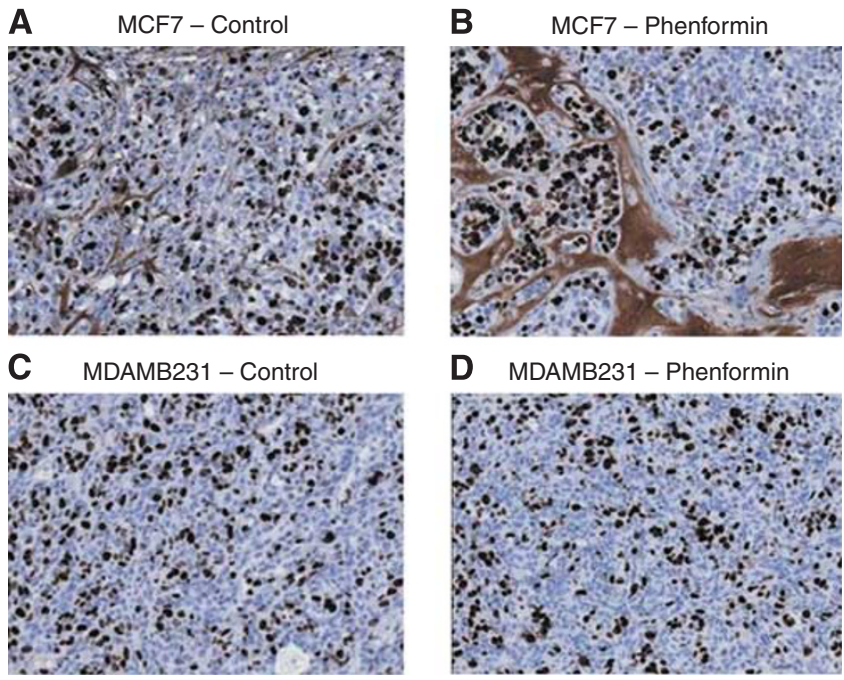

Figure 5 Ki67 immunohistochemistry analysis of MCF7 and MDAMB23। xenografts treated with phenformin. Tumours were harvested and immunohistochemistry analysis performed as described in Materials and methods. No significant differences were observed for MCF7 tumour treated with phenformin compared with control $(\mathbf{A}$ and $\mathbf{B})$. Similar results were found for MDAMB23 I tumours $(\mathbf{C}$ and $\mathbf{D}), \times 5$ magnified image captured with an Aperio ScanScope XT, Aperio Technologies.

$\begin{array}{llllllllllllll}1 & 2 & 3 & 4 & 5 & 6 & 7 & 8 & 9 & 10 & 11 & 12 & 13\end{array}$

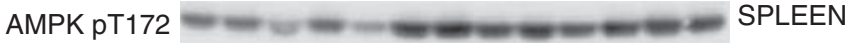

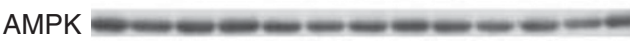

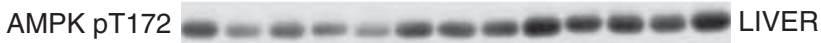

AMPK $\ldots-\ldots-\cdots \cdots \cdots$

GAPDH $\frac{-1-1-\cdots}{\text { Control }} \frac{-1-\cdots}{\text { PHEN }}$

Figure 6 AMPK activation in liver and spleen of mice. Liver and spleen of control mice and mice that were pre-treated or treated after xenograft establishment with $300 \mathrm{mg} \mathrm{kg}^{-1}$ phenformin were processed and western blots produced as described in Materials and methods. Lanes I-4 show the results for control mice, lanes 5-9 show the results for mice pretreated with phenformin and lanes 10-13 show the results for mice treated with phenformin. Phosphorylation of the activation loop of AMPK (TI 72) was enhanced in liver and spleen from mice pre-treated or treated (lanes 10-13) with phenformin compared with untreated control mice.

$\begin{array}{llllllllllllll}1 & 2 & 3 & 4 & 5 & 6 & 7 & 8 & 9 & 10 & 11 & 12 & 13\end{array}$

$\begin{aligned} & \text { AMPK p172 } \text { TUMOURS } \\ & \text { AMPK } \text { Control } \\ &{ } }\end{aligned}$

Figure 7 AMPK activation in MDAMB23I xenograft tumours. Tumours of control mice and mice that were pre-treated or treated with $300 \mathrm{mg} \mathrm{kg}^{-}$ phenformin were processed and western blots produced as described in Materials and methods. Lanes I-5 show the results for control mice, lanes 6-9 for mice pre-treated with phenformin and lanes $10-13$ for mice treated with phenformin. Phosphorylation of the activation loop of AMPK (TI 72) was enhanced in most of the tumours from mice pre-treated or treated with phenformin compared with untreated control mice.

\section{DISCUSSION}

This study has demonstrated the efficacy of phenformin in vivo in the prevention and growth reduction of ER-positive, luminal A, MCF7 and triple-negative MDAMB231 xenograft tumours in immunocompromised mice. Phenformin demonstrated greater inhibition of MDAMB231 tumour growth than metformin in treated animals. Resistance to metformin by MDAMB231 has been reported by other authors (Zhuang and Miskimins, 2011). The fact that phenformin treatment may lead to lactic acidosis whereas metformin does not suggests that these biguanides work through the pathways that are not identical, which may account for the difference in sensitivity by MDAMB231.

There was a significant decrease in the number of mitotic figures in treated tumours compared with untreated controls for both cell line-derived xenograft models withno change in the number of apoptotic cells, suggesting cell-cycle arrest. This is consistent with AMPK-induced cell-cycle arrest in hepatoma HepG2 cells (Imamura et al, 2001), human aortic smooth muscle cells, rabbit aortic strip (Igata et al, 2005) and mouse embryonic fibroblasts (Jones et al, 2005).

MCF7, but not MDAMB231, tumours treated with phenformin showed a substantial increase in stromal connective tissue (Figures $3 \mathrm{~A}$ and $\mathrm{B}$ ) compatible with effects of the drug on activated fibroblasts (Olumi et al, 1999; Bhowmick and Moses, 2005). The increased stroma associated with a decrease in mitotic figure numbers observed for MCF7 tumours treated with phenformin is consistent with a stroma not supportive of tumour growth. Although stroma is usually considered to be associated with invasion and metastasis, there have been reports of stroma formation that inhibits the growth of several cancers in a mode of action that may be due to the formation of tumour stroma not supportive of tumour growth (Skobe et al, 1997; Meyerhardt and Mayer, 2005; Chlenski et al, 2006, 2007). Moreover, our results for cleaved PARP or phospho-histone $\mathrm{H} 3$ immunohistochemistry with no increase in pre-treated/treated tumours compared with controls are supportive of the cell-cycle arrest hypothesis. Cell proliferation, measured by Ki67, was not significantly lower in either of the phenformin-treated tumour groups compared with controls (Figure 5). However, there was a significant decrease in the number of mitotic figures in treated tumours compared with untreated controls for both cell lines with no change in the number of apoptotic cells, suggesting cell-cycle arrest. This underlines that Ki67 fraction and mitotic activity index are not necessarily interchangeable in these breast cancer xenograft models and may represent differences in the kinetics of cell-cycle progression (Rudolph et al, 1998; Jalava et al, 2006).

AMPK activation was observed by western blots using phosphospecific antibodies in the liver, spleen and tumours of mice treated or pre-treated with phenformin, consistent with a proposed mechanism of action of biguanides involving AMPK activation leading to mTORC1 inhibition (Zhang et al, 2007; Hadad et al, 2008).

\section{CONCLUSION}

Phenformin significantly inhibited both the development and growth of established MCF7 and MDAMB231 tumours without murine toxicity. The potential for phenformin should be considered further as an antineoplastic agent of greater in vivo efficacy than metformin for the treatment of breast cancer.

\section{ACKNOWLEDGEMENTS}

We would like to thank the Breast Cancer Research, Scotland, for financial support. 


\section{REFERENCES}

Anisimov VN, Berstein LM, Egormin PA, Piskunova TS, Popovich IG, Zabezhinski MA, Kovalenko IG, Poroshina TE, Semenchenko AV, Provinciali M, Re F, Franceschi C (2005) Effect of metformin on life span and on the development of spontaneous mammary tumours in HER-2/neu transgenic mice. Exp Gerontol 40: 685-693

Anisimov VN, Egormin PA, Piskunova TS, Popovich IG, Tyndyk ML, Yurova MN, Zabezhinski MA, Anikin IV, Karkach AS, Romanyukha AA (2010) Metformin extends life span of HER-2/neu transgenic mice and in combination with melatonin inhibits growth of transplantable tumours in vivo. Cell Cycle 9: 188-197

Bailey CJ, Turner RC (1996) Metformin. N Engl J Med 334: 574-579

Bhowmick NA, Moses HL (2005) Tumour-stroma interactions. Curr Opin Genet Dev 15: $97-101$

Caraci F, Chisari M, Frasca G, Chiechio S, Salmone S, Pinto A, Sortino MA, Bianchi A (2003) Effects of phenformin on the proliferation of human tumor cell lines. Life Sci 74(5): 643-650

Chlenski A, Guerrero LJ, Yang Q, Tian Y, Peddinti R, Salwen HR, Cohn SL (2007) SPARC enhances tumour stroma formation and prevents fibroblast activation. Oncogene 26: 4513-4522

Chlenski A, Guerrero LJ, Yang Q, Tian Y, Salwen HR, Zage P, Cohn SL (2006) SPARC expression is associated with impaired tumour growth, inhibited angiogenesis and changes in the extracellular matrix. Int $J$ Cancer 118: $310-316$

Chong CR, Chabner BA (2009) Mysterious metformin. Oncologist 14: 1178- 1181

Demierre MF, Nathanson L (2003) Chemoprevention for melanoma: an unexplored strategy. J Clin Oncol 21: 158-165

Dilman VM, Anisimov VN (1979) Potentiation of antitumour effect of cyclophosphamide and hydrazine sulfate by treatment with the antidiabetic agent, 1-phenylethylbiguanide (phenformin). Cancer Lett 7: 357-361

Dilman VM, Anisimov VN (1980) Effect of treatment with phenformin, diphenylhydantoin or L-dopa on life span and tumour incidence in C3H/Sn mice. Gerontology 26: 241 - 246

Dilman VM, Berstein LM, Zabezhinski MA, Alexandrov VA, Bobrov JF, Pliss GB (1978) Inhibition of DMBA induced carcinogenesis by phenformin in the mammary gland of rats. Archiv Geschwulstforsch 48: 1-8

Evans JM, Donnelly LA, Emslie-Smith AM, Alessi DR, Morris AD (2005) Metformin and reduced risk of cancer in diabetic patients. BMJ 330: $1304-1305$

Goodwin PJ, Ligibel JA, Stambolic V (2009) Metformin in breast cancer: time for action. J Clin Oncol 27: 3271-3273

Hadad SM, Fleming S, Thompson AM (2008) Targeting AMPK: a new therapeutic opportunity in breast cancer. Crit Rev Oncol Hematol 67: 1-7

Hadad S, Iwamoto T, Jordan L, Purdie C, Bray S, Baker L, Jellema G, Deharo S, Hardie DG, Pusztai L, Moulder-Thompson S, Dewar JA, Thompson AM (2011) Evidence for biological effects of metformin in operable breast cancer: a pre-operative, window-of-opportunity, randomized trial. Breast Cancer Res Treat 128(3): 783-794

Huang X, Wullscheleger S, Shpiro N, McGuire VA, Sakamoto K, Woods YL, McBurnie W, Fleming S, Alessi DR (2008) Important role of the LKB1 AMPK pathway in suppressing tumourigenesis in PTEN-deficient mice. Biochem J 412: $211-221$

Igata $\mathrm{M}$, Motoshima $\mathrm{H}$, Tsuruzoe $\mathrm{K}$, Kojima $\mathrm{K}$, Matsumura $\mathrm{T}$, Kondo T, Taguchi T, Nakamaru K, Yano M, Kukidome D, Matsumoto K, Toyonaga T, Asano T, Nishikawa T, Araki E (2005) Adenosine monophosphateactivated protein kinase suppresses vascular smooth muscle cell proliferation through the inhibition of cell cycle progression. Circ Res 97(8): $837-844$

Imamura K, Ogura T, Kishimoto A, Kaminishi M, Esumi H (2001) Cell cycle regulation via $\mathrm{p} 53$ phosphorylation by a $5^{\prime}$-AMP activated protein kinase activator, 5-aminoimidazole-4-carboxamide-1-beta-D-ribofuranoside, in a human hepatocellular carcinoma cell line. Biochem Biophys Res Commun 287(2): $562-567$

Jalava P, Kuopio T, Juntti-Patinen L, Kotkansalo T, Kronqvist P, Collan Y (2006) Ki67 immunohistochemistry: a valuable marker in prognostication but with a risk of misclassification: proliferation subgroups formed based on Ki67 immunoreactivity and standardized mitotic index. Histopathology 48: 674-682

Jiralerspong S, Palla SL, Giordano SH, Meric-Bernstam F, Liedtke C, Barnett CM, Hsu L, Hung MC, Hortobagyi GN, Gonzalez-Angulo AM
(2009) Metformin and pathologic complete responses to neoadjuvant chemotherapy in diabetic patients with breast cancer. J Clin Oncol 27: $3297-3302$

Jones RG, Plas DR, Kubek S, Buzzai M, Mu J, Xu Y, Birnbaum MJ, Thompson CB (2005) AMP-activated protein kinase induces a p53-dependent metabolic checkpoint. Mol Cell 18(3): 283-293

Kahn BB, Alquier T, Carling D, Hardie DG (2005) AMP-activated protein kinase: ancient energy gauge provides clues to modern understanding of metabolism. Cell Metab 1: 15-25

Kim YD, Park KG, Lee YS, Park YY, Kim DK, Nedumaran B, Jang WG, Cho WJ, Ha J, Lee IK, Lee CH, Chois HS (2008) Metformin inhibits hepatic gluconeogenesis through AMP-activated protein kinase-dependent regulation of the orphan nuclear receptor SHP. Diabets 57: 306-314

Kirpichnikov D, McFarlane SI, Sowers JR (2002) Metformin: an update. Ann Intern Med 137: 25-33

Lain S, Hollick JJ, Campbell J, Staples OD, Higgins M, Aoubala M, McCarthy A, Appleyard V, Murray KE, Baker L, Thompson A, Mathers J, Holland SJ, Stark MJ, Pass G, Woods J, Lane DP, Westwood NJ (2008) Discovery in vivo activity, and mechanism of action of a small-molecule p53 activator. Cancer Cell 13: 454-463

Landman GW, Kleefstra N, van Hateren KJ, Groenier KH, Gans RO, Bilo HJ (2010) Metformin associated with lower cancer mortality in type 2 diabetes: ZODIAC-16. Diabetes Care 33: 322-326

Lea MA, Chacko J, Lolikals S, Hong JY, Chung R, Ortega A, desbordes C (2011) Addition of 2-deoxyglucose enhances growth inhibition but reverses acidification in colon cancer cells treated with phenformin. Anticancer Res 31(2): 421-426

Liu B, Fan Z, Edgerton SM, Deng XS, Alimova IN, Lind SE, Thor AD (2009) Metformin induces unique biological and molecular responses in triple negative breast cancer cells. Cell Cycle 8: 2031-2040

Lugaro G, Giannattasio G (1968) Effect of biguanides on the respiration of tumour cells. Experientia 24(8): 794-795

McGuinness ME, Talbert RL (1993) Phenformin-induced lactic acidosis: a forgotten adverse drug reaction. Ann Pharmacother 27: 1183-1187

Meyerhardt JA, Mayer RJ (2005) Systemic therapy for colorectal cancer. $N$ Engl J Med 352: 476-487

Olumi AF, Grossfeld GD, Hayward SW, Carroll PR, Tlsty TD, Cunha GR (1999) Carcinoma-associated fibroblasts direct tumour progression of initiated human prostatic epithelium. Cancer Res 59: 5002-5011

Rudolph P, Peters J, Lorenz D, Schmidt D, Parwaresch R (1998) Correlation between mitotic and $\mathrm{Ki}-67$ labeling indices in paraffin-embedded carcinoma specimens. Hum Pathol 29: 1216-1222

Sausville EA, Elsayed Y, Monga M, Kim G (2003) Signal transductiondirected cancer treatments. Annu Rev Pharmacol Toxicol 43: 199-231

Shaw RJ, Lamia KA, Vasquez D, Koo SH, Bardeesy N, Depinho RA, Montminy M, Cantley LC (2005) The kinase LKB1 mediates glucosehomeostasis in liver and therapeutic effects of metformin. Science 310: $1642-1646$

Skobe M, Rockwell P, Goldstein N, Vosseler S, Fusenig NE (1997) Halting angiogenesis suppresses carcinoma cell invasion. Nat Med 3: $1222-1227$

Staples OD, Hollick JJ, Campbell J, Higgins M, McCarthy AR, Appleyard V, Murray KE, Baker L, Thompson A, Ronseaux S, Slawin AM, Lane DP, Westwood NJ, Lain S (2008) Characterization, chemical optimization and anti-tumour activity of a tubulin poison identified by a p53-based phenotypic screen. Cell Cycle 7: 3417-3427

Zhang L, He H, Balschi JA (2007) Metformin and phenformin activate AMP-activated protein kinase in the heart by increasing cytosolic AMP concentration. Am J Physiol Heart Circ Physiol 293: 457-466

Zhou G, Myers R, Li Y, Chen Y, Shen X, Fenyk-Melody J, Wu M, Ventre J, Doebber T, Fujii N, Musi N, Hirshman M, Goodyear L, Moller D (2001) Role of AMP-activated protein kinase in mechanism of metformin action. J Clin Invest 108: $1167-1174$

Zhuang Y, Miskimins WK (2008) Cell cycle arrest in Metformin treated breast cancer cells involves activation of AMPK, downregulation of cyclin D1, and requires p27Kip1 or p21Cip1. J Mol Signal 1: 3-18

Zhuang Y, Miskimins WK (2011) Metformin induces both caspasedependent and poly(ADP-ribose) polymerase-dependent cell death in breast cancer cells. Mol Cancer Res 9(5): 603-615

This work is published under the standard license to publish agreement. After 12 months the work will become freely available and the license terms will switch to a Creative Commons Attribution-NonCommercial-Share Alike 3.0 Unported License. 